\title{
Determining brain death in adults
}

\author{
Eelco F.M. Wijdicks, MD
}

Overview. The Quality Standards Subcommittee of the American Academy of Neurology (AAN) is charged with developing guidelines for neurologists for diagnostic procedures, treatment modalities, and clinical disorders. The present document is intended to provide background for the report "Practice Parameters for Determining Brain Death in Adults" (in this issue), which has been produced by the Quality Standards Subcommittee of the AAN and approved by the AAN Executive Board. This document outlines diagnostic criteria for the clinical diagnosis of brain death in patients older than 18 years. The recommendations for diagnosis in neonates and children have been published as a position paper by the American Academy of Pediatrics ${ }^{1}$; in addition, a review paper can be consulted. ${ }^{2}$ The sensitivity and specificity of laboratory tests that confirm the clinical diagnosis of brain death are discussed.

Justification. Brain death is seen frequently as a result of severe head injury, aneurysmal subarachnoid hemorrhage, and intracerebral hemorrhage. . $^{3-6}$ In medical and surgical intensive care units, large ischemic strokes associated with brain swelling and herniation, hypoxic-ischemic encephalopathy after prolonged cardiac resuscitation or asphyxia, and massive brain edema in patients with fulminant hepatic necrosis are the most common causes of brain death. ${ }^{7-9}$ In large referral hospitals, neurologists or neurosurgeons may diagnose brain death from 25 to 30 times a year. ${ }^{10-14}$

The clinical diagnosis of brain death has never been easy for most physicians, including neurologists and neurosurgeons.

Brain death was selected as a topic for practice parameters because of a perceived need for standardized clinical examination criteria for the diagnosis of brain death in adults, large differences in practice in performing the apnea test, ${ }^{11}$ and controversies over appropriate utilization of confirmatory tests. ${ }^{11}$ In addition, government and third-party payers are demanding well-defined practice parameters in the clinical examination or confirmatory testing. New parameters are needed to add to the report of the medical consultants on the diagnosis of death submitted to the President's Commission for the Study of Ethical Problems in Medicine and Biomedical and Behavioral Research, published in 1981. ${ }^{15}$ The areas of need are as follows:

1. Unequivocal definition of clinical testing of brainstem function;

2. Description of conditions that may completely or partly mimic brain death;

3 . Interpretation of clinical observations that are compatible with brain death but initially may suggest otherwise;

4. Clear description of apnea testing procedure;

5. Indications of confirmatory laboratory tests;

6. Validity and reproducibility of confirmatory laboratory tests; and

7. Initial practice guidelines for organ procurement.

Development of practice parameters. All literature pertaining to brain death was identified by MEDLINE for the years 1976 to 1994 . Key words used were "brain death" and "apnea test" with the subheading "adult." Peer-reviewed articles with original work were selected. Selection for this document was based on the quality of the original work. Current textbooks and handbooks of neurology, medicine, intensive care, pulmonology, and anesthesia were reviewed for opinion. References were categorized as class II (well-designed clinical studies) or class III (case reports, uncontrolled studies, and expert opinion). (Class II or III studies are identified by a " $I \Gamma$ " or "III" in the list of references.) Class I studies (randomized clinical trials) were not available. The committee defined practice parameters as standards (generally accepted principles for patient management that reflect a high degree of clinical certainty); guidelines (recommendations for patient management that may identify a particular strategy and that reflect moderate clinical certainty); and options (strategies for patient management for which certainty is unclear). All suggestions in this document should be considered guidelines unless otherwise specified. Consensus was achieved by group discussion.

See also page 1012

From the Department of Neurology, Mayo Clinic and Mayo Foundation, Rochester, MN.

Portions of this manuscript were published in Wijdicks EFM, Neurology of critical illness. Philadelphia: F.A. Davis Co, 1995:chapter 18. By permission of Mayo Foundation.

Received October 4, 1994. Accepted in final form October 10, 1994.

Address correspondence and reprint requests to Dr. Eelco F.M. Wijdicks, Department of Neurology, Mayo Clinic, 200 First Street SW, Rochester, MN 55905 . 
Background. The President's Commission for the Study of Ethical Problems in Medicine and Biomedical and Behavioral Research ${ }^{15}$ defined "brain death" as irreversible cessation of all functions of the entire brain, including the brainstem. The clinical diagnosis of brain death is equivalent to irreversible loss of all brainstem function. Of particular importance in the clinical examination of patients who are brain-dead are (1) documentation of loss of consciousness, (2) no motor response to pain stimuli, (3) no brainstem reflexes, and (4) apnea. In the vast majority of patients, CT documents an abnormality that explains loss of brain and brainstem function. The clinical diagnosis of brain death should be in doubt in patients with normal CT or CSF findings. Nonetheless, occasional patients have an ischemic-anoxic insult to the brain that results in brain death without CT abnormality. In these patients, the clinical diagnosis of brain death should be made only if there is a high degree of certainty about the mechanism that led to brain death.

The diagnosis of brain death in patients with coma of undetermined origin is very complex. No studies have been reported that address this specific clinical dilemma. If a patient meets the clinical criteria, has a prolonged period of observation ( $>24$ hours), and has no cerebral blood flow, and if confounding factors have been excluded, it is reasonable to make a diagnosis of brain death. Organ donation can be allowed if no transmittable disease (eg, rabies encephalitis) is present.

Confounding factors that mimic or partly mimic brain death should be excluded. First, hypothermia may blunt brainstem reflexes but only when rectal temperatures are below $32{ }^{\circ} \mathrm{C}$. Brainstem reflexes have been absent in patients with rectal temperatures below $27^{\circ} \mathrm{C} .{ }^{16}$ It is not known whether patients with a major CNS catastrophe are susceptible at higher core temperatures. Second, drug intoxication should be excluded if the history is suggestive. In this situation, routine drug screens may be helpful but probably only when testing is requested for a specific drug or poison. The diagnosis of brain death most likely can be made when levels of barbiturates in the blood are subtherapeutic, although data in adults are sparse. In brain-dead children with therapeutic levels of barbiturates, no change in isoelectric EEGs was noted during decrease of barbiturates in the blood to subtherapeutic or undetectable levels. ${ }^{17}$ Third, the clinical diagnosis of brain death is probably not reliable in patients investigated at the time of an acute metabolic or endocrine derangement. ${ }^{15,18-20}$

An important component of the clinical diagnosis of brain death is the demonstration of apnea. Misconceptions about the procedure are frequently encountered in clinical practice. ${ }^{11}$ Loss of brainstem function produces loss of breathing and vasomotor control that results in apnea and hypotension. Hypotension is frequently present at the time of the clinical diagnosis of brain death, but patients may have normal blood pressure despite fulfilling the clinical criteria of brain death. ${ }^{21}$

The respiratory neurons are controlled by central chemoreceptors that sense changes in the $\mathrm{PCO}_{2}$ and $\mathrm{pH}$ of the CSF, and these accurately reflect changes in plasma $\mathrm{PCO}_{2}{ }^{22}$ There are many other mechanical and chemical stimuli and inhibitory influences on the respiratory neurons of the brainstem.

It is not known at what arterial $\mathrm{PCO}_{2}$ level the chemoreceptors of the respiratory center are maximally stimulated in hyperoxygenated patients with brainstem destruction. Target arterial $\mathrm{PCO}_{2}$ levels are derived from a small number of patients who had respiratory efforts after induction of hypercarbia but who otherwise fulfilled the criteria for the clinical diagnosis of brain death. ${ }^{21}$ The advisory guidelines for the determination of death submitted to the President's Commission for the Study of Ethical Problems in Medicine and Biomedical and Behavioral Research are based on these observations. ${ }^{15}$ That document recommends $\mathrm{PaCO}_{2}$ levels greater than $60 \mathrm{~mm} \mathrm{Hg}$ for maximal stimulation of the brainstem. Lower target levels have been suggested because four patients made effective normal breathing efforts at lower $\mathrm{PCO}_{2}$ values (range, 30 to $37 \mathrm{~mm} \mathrm{Hg}$; mean, $34 \mathrm{~mm} \mathrm{Hg}$ ). At higher $\mathrm{PCO}_{2}$ values (range, 41 to $51 \mathrm{~mm} \mathrm{Hg}$ ), respiratory-like movements have been observed. ${ }^{21}$ These movements are ineffective for ventilation and consist of shoulder elevation and adduction, back arching, and intercostal expansion. These respiratory-like efforts produce negligible tidal volumes and virtually no inspiratory force. ${ }^{21}$ Less reliable targets for $\mathrm{PCO}_{2}$ may be obtained from anesthetized subjects $\left(\mathrm{PCO}_{2} \text { of } 30 \mathrm{~mm} \mathrm{Hg}\right)^{23,24}$ or in experiments with breath-holding $\left(\mathrm{PCO}_{2} \text { of } 40 \text { to } 45 \mathrm{~mm} \mathrm{Hg}\right)^{25-27}$

The target $\mathrm{PCO}_{2}$ levels of the apnea tests in brain death determination may be higher in patients with chronic hypercapnia. Typically, these patients have severe chronic obstructive pulmonary disease, bronchiectasis, sleep apnea, and morbid obesity. ${ }^{27,28}$ If metabolic acidosis is not present, chronic hypercarbia (" $\mathrm{CO}_{2}$ retainers") can be suspected in patients with high initial serum concentrations of bicarbonate. When initial arterial blood gas determination confirms chronic hypercarbia, additional noninvasive confirmatory tests are strongly encouraged.

Low arterial $\mathrm{PCO}_{2}$ values can be expected in patients with acute catastrophic structural CNS damage. In many instances, hypocarbia is caused by high tidal volumes associated with mechanical ventilation, by hyperventilation instituted to decrease intracranial pressure, or by hypothermia. Hypocarbia can be corrected by changing the minute volume by decreasing either rate or tidal volume for several minutes. Correction of hypocarbia probably should not be done with $\mathrm{CO}_{2}$ mixtures. Although administration of $5 \%$ $\mathrm{CO}_{2}$ in oxygen will elevate $\mathrm{PCO}_{2}$ by $17.3 \mathrm{~mm} \mathrm{Hg}$ in 1 to 2 minutes, this procedure may rapidly lead to severe hypercarbia and respiratory acidosis. ${ }^{24}$ 


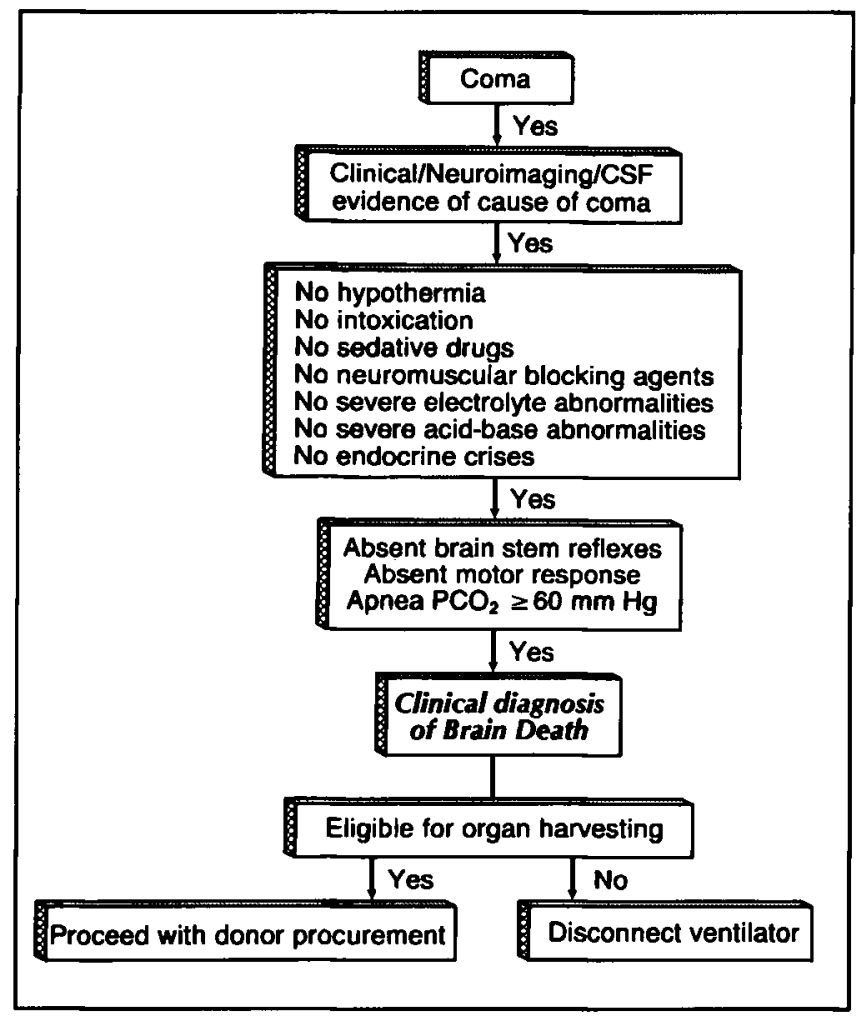

Figure 1. Proposed guidelines for the clinical diagnosis of brain death.

Apnea testing is easy with a starting arterial $\mathrm{PCO}_{2}$ value of $40 \mathrm{~mm} \mathrm{Hg}$ because the target level of $60 \mathrm{~mm} \mathrm{Hg}$ is reached after 6 to 8 minutes of disconnection from the ventilator. ${ }^{12,29-32}$ The estimated $\mathrm{PCO}_{2}$ increase is from 3 to $6 \mathrm{~mm} \mathrm{Hg}$ per minute and varies with the rate of $\mathrm{CO}_{2}$ production. Cardiac arrhythmias are side effects of hypercarbia and respiratory acidosis, occurring mostly in patients with hypoxia. ${ }^{33}$ The most common abnormalities are premature ventricular contractions and ventricular tachycardia. ${ }^{33}$ Severe hypotension (change in mean arterial blood pressure of more than $15 \%$ ) has been observed in well-oxygenated patients in whom $\mathrm{PCO}_{2}$ values reached very high levels (average, $90 \mathrm{~mm}$ $\mathrm{Hg}$ ) from acidosis alone. ${ }^{34}$ Administration of $100 \%$ $\mathrm{O}_{2}$ through a catheter placed at the level of the carina secures adequate oxygenation during apnea testing. A recent study of 70 apnea tests found no significant hypoxemia after previous oxygenation and placement of a catheter inside the endotracheal tube. ${ }^{34}$ Oxygenation may be inadequate, for example, in patients with severe pulmonary disease, acute respiratory distress syndrome, or neurogenic pulmonary edema. ${ }^{33}$

The clinical diagnosis of brain death includes apnea with an arterial $\mathrm{PCO}_{2}$ of $60 \mathrm{~mm} \mathrm{Hg}$. However, there have been only a few studies of the methods of testing, and the literature does not provide evidence to favor one method over the other.

Clinical diagnosis of brain death. Brain death is the absence of clinical brain function when the proximate cause is known and demonstrably irreversible. To overcome the possible pitfalls of making the diagnosis of brain death, the following prerequisites are proposed (figure 1): (1) there must be definite clinical or neuroimaging evidence of an acute CNS catastrophe that is compatible with brain death; (2) complicating medical conditions that may confound clinical assessment should be excluded (no severe electrolyte, severe acid-base, or severe endocrine disturbance); (3) drug intoxication or poisoning must be absent; and (4) core temperature must be at least $32{ }^{\circ} \mathrm{C}$. Testing of brainstem function can proceed only after these precautions have been taken.

The three cardinal findings in brain death are coma or unresponsiveness, absence of brainstem reflexes, and apnea. The clinical examination of the brainstem includes testing of brainstem reflexes, determination of the patient's ability to breath spontaneously, and evaluation of motor responses to pain.

I. Coma or unresponsiveness

A. Motor responses of the limbs

1. Testing. Motor responses of the limbs to painful stimuli should be absent after supraorbital pressure and nail-bed pressure stimulus.

2. Pitfalls. Motor responses ("Lazarus sign") ${ }^{14}$ may occur spontaneously during apnea testing, often during hypoxic or hypotensive episodes, and are of spinal origin. Neuromuscular blocking agents can produce prolonged weakness. ${ }^{35}$ If neuromuscular blocking agents have recently been administered, examination with a bedside peripheral nerve stimulator is needed. ${ }^{36} \mathrm{~A}$ trainof-four stimulus should result in four thumb twitches.

II. Absence of brainstem reflexes

\section{A. Pupils}

1. Testing. The response to bright light should be absent in both eyes. Round, oval, or irregularly shaped pupils are compatible with brain death. Most pupils in brain death are in middle position (4 to $6 \mathrm{~mm}$ ), but the size of the pupils may vary from 4 to $9 \mathrm{~mm}$. Dilated pupils are compatible with brain death because intact sympathetic cervical pathways connected with the radially arranged fibers of the dilator muscle may remain intact. ${ }^{5,37}$

2. Pitfalls. Many drugs can influence pupil size, but light response remains intact. In conventional doses, atropine given intravenously has no marked influence on pupillary response. ${ }^{38,39} \mathrm{~A}$ report of fixed, dilated pupils after extremely high doses of dopamine has not been confirmed. ${ }^{40}$

Because nicotine receptors are absent in the iris, neuromuscular blocking drugs do not noticeably influence pupil size. Topical 
ocular instillation of drugs and trauma to the cornea or bulbus oculi may cause abnormalities in pupil size and can produce nonreactive pupils. Preexisting anatomic abnormalities of the iris or effects of previous surgery should be exchuded.

B. Ocular movements

1. Testing. Ocular movements are absent after head-turning and caloric testing with ice water. ${ }^{4.5}$ (Testing is done only when no fracture or instability of the cervical spine is apparent, and in patients with head injury, the cervical spine must be imaged to exclude potential fractures or instability or both.) The oculocephalic reflex, elicited by fast and vigorous turning of the head from middle position to $90^{\circ}$ on both sides, normally results in eye deviation to the opposite side of the head-turning. Vertical eye movements should be tested with brisk neck flexion. Eyelid opening and vertical and horizontal eye movements must be absent in brain death.

Caloric testing should be done with the head elevated to $30^{\circ}$ during irrigation of the tympanum on each side with $50 \mathrm{ml}$ of ice water. Tympanum irrigation can be best accomplished by inserting a small suction catheter into the external auditory canal and connecting it to a $50-\mathrm{ml}$ syringe filled with ice water. Tonic deviation of the eyes directed to the cold caloric stimulus is absent. The investigator should allow up to 1 minute after injection, and the time between stimulation on each side should be at least 5 minutes.

2. Pitfalls. Drugs that can diminish or completely abolish the caloric response are sedatives, aminoglycosides, tricyclic antidepressants, anticholinergics, antiepileptic drugs, and chemotherapeutic agents. ${ }^{41,42}$ After closed head injury or facial trauma, lid edema and chemosis of the conjunctiva may restrict movement of the globes. Clotted blood or cerumen may diminish the caloric response, and repeat testing is required after direct inspection of the tympanum. Basal fracture of the petrous bone abolishes the caloric response only unilaterally and may be identified by an ecchymotic mastoid process.

C. Facial sensation and facial motor response

1. Testing. Corneal reflexes should be tested with a throat swab. Corneal reflex and jaw reflex should be absent. Grimacing to pain can be tested by applying deep pressure with a blunt object on the nail beds, pressure on the supraorbital ridge, or deep pressure on both condyles at the level of the temporomandibular joint.

2. Pitfall. Severe facial trauma may limit interpretation of all brainstem reflexes.

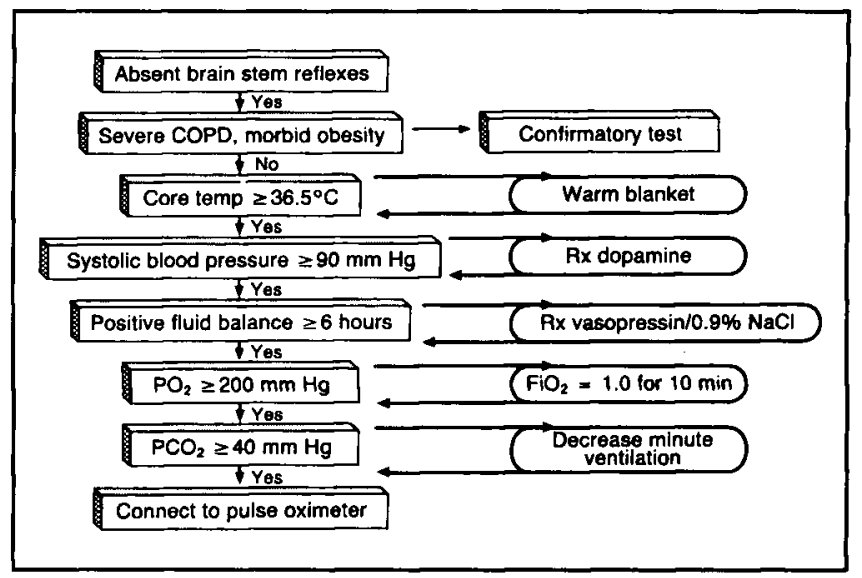

Figure 2. Prerequisites for the apnea test in brain death. $C O P D=$ chronic obstructive pulmonary disease .

D. Pharyngeal and tracheal reflexes

1. Testing. The gag response, tested by stimulation of the posterior pharynx with a tongue blade, should be absent. Lack of cough response to bronchial suctioning should be demonstrated.

2. Pitfall. In orally intubated patients, the gag response may be difficult to interpret.

III. Apnea

Apnea test (guidelines for testing)

1. Prerequisites (figure 2). Important changes in vital signs (eg, marked hypotension, severe cardiac arrhythmias) during the apnea test may be related to lack of adequate precautions, although they may occur spontaneously during increasing acidosis. Therefore, the following prerequisites are suggested: (1) core temperature greater than or equal to $36.5^{\circ} \mathrm{C}\left(4.5^{\circ} \mathrm{C}\right.$ higher than the required $32{ }^{\circ} \mathrm{C}$ for clinical diagnosis of brain death), (2) systolic blood pressure greater than or equal to $90 \mathrm{~mm} \mathrm{Hg}$, (3) euvolemia (option: preferably positive fluid balance in the previous 6 hours), (4) eucapnia (option: arterial $\mathrm{PCO}_{2}$ greater than or equal to 40 $\mathrm{mm} \mathrm{Hg}$ ), and (5) normoxemia (option: arterial $\mathrm{PO}_{2}$ greater than or equal to $200 \mathrm{~mm}$ $\mathrm{Hg}$ ). A pulse oximeter is connected to the patient.

2. Testing (figure 3)

- Disconnect the ventilator.

- Deliver $100 \% \mathrm{O}_{2}, 6 \mathrm{l} / \mathrm{min}$. Option: place a cannula at the level of the carina.

- Look closely for respiratory movements. Respiration is defined as abdominal or chest excursions that produce adequate tidal volumes. If present, respiration can be expected early in the apnea test. When respiratory-like movements occur, they can be expected at the end of the apnea test, when oxygenation may become marginal. When the result is in doubt, a spirometer can be connected to the patient to confirm that tidal volumes are absent. 


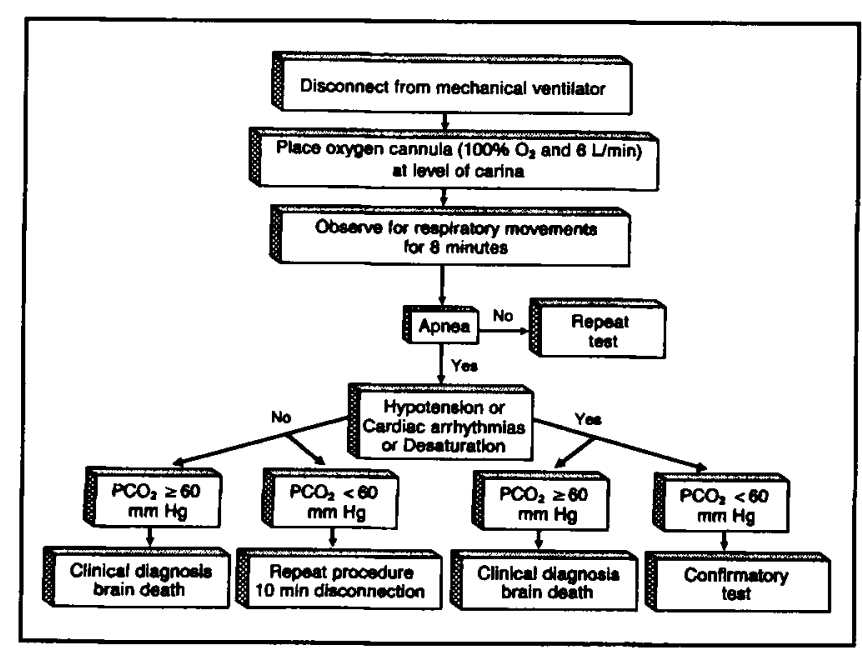

Figure 3. Procedure for the apnea test in brain death.

- Measure arterial $\mathrm{PO}_{2}, \mathrm{PCO}_{2}$, and $\mathrm{pH}$ after approximately 8 minutes and reconnect the ventilator.

- If respiratory movements are absent and arterial $\mathrm{PCO}_{2}$ is equal to or greater than $60 \mathrm{~mm} \mathrm{Hg}$ (option: $20 \mathrm{~mm} \mathrm{Hg}$ increase in $\mathrm{PCO}_{2}$ over a baseline normal $\mathrm{PCO}_{2}$ ), the apnea test result is positive (ie, it supports the clinical diagnosis of brain death).

- If respiratory movements are observed, the apnea test result is negative (ie, it does not support the clinical diagnosis of brain death), and the test should be repeated.

- If, during apnea testing, the systolic blood pressure becomes $\leq 90 \mathrm{~mm} \mathrm{Hg}$, the pulse oximeter indicates marked desaturation, and cardiac arrhythmias occur, immediately draw a sample, connect the ventilator, and analyze arterial blood gas. The apnea test result is positive if arterial $\mathrm{PCO}_{2}$ is greater than or equal to $60 \mathrm{~mm} \mathrm{Hg}$ or $\mathrm{PCO}_{2}$ increase is equal to or greater than $20 \mathrm{~mm}$ $\mathrm{Hg}$ above baseline normal $\mathrm{PCO}_{2}$. If arterial $\mathrm{PCO}_{2}$ is less than $60 \mathrm{~mm} \mathrm{Hg}$ or $\mathrm{PCO}_{2}$ increase is less than $20 \mathrm{~mm} \mathrm{Hg}$ over baseline normal $\mathrm{PCO}_{2}$, the result is indeterminate. In this situation of cardiovascular instability together with uncertainty about the upper limit of $\mathrm{PCO}_{2}$ at which maximal stimulation of the respiratory center occurs, it is left to the discretion of the physician whether a confirmatory test is needed to finalize the clinical diagnosis of brain death.

- If no respiratory movements are observed, $\mathrm{PCO}_{2}$ is less than $60 \mathrm{~mm} \mathrm{Hg}$, and no significant cardiac arrhythmia or hypotension is observed, the test may be repeated with 10 minutes of apnea.

Clinical observations compatible with the diagnosis of brain death. Respiratory acidosis, hypoxia, or brisk neck flexion may generate spinal cord responses. ${ }^{14,36,43,44}$
Spontaneous movements of the limbs from spinal mechanisms can occasionally occur and are more frequent in young adults. These spinal reflexes include rapid flexion in arms, raising of all limbs off the bed, grasping movements, spontaneous jerking of one leg, walking-like movements, and movements of the arms up to the point of reaching the endotracheal tube. ${ }^{14}$

Respiratory-like movements may also occur and are typical agonal breathing patterns. They are characterized by shoulder elevation and adduction, back arching, and intercostal expansion without any significant tidal volume.

Other responses are profuse sweating, blushing, tachycardia, and sudden increases in blood pressure. ${ }^{33,46}$ These hemodynamic responses can sometimes be elicited by neck flexion, and they can be eliminated by ganglion blockers (eg, trimethaphan). ${ }^{44}$ Normal blood pressure and absence of diabetes insipidus without pharmacologic support are compatible with brain death. Muscle stretch reflexes, superficial abdominal reflexes, and Babinski reflexes are of spinal origin and do not invalidate a diagnosis of brain death. Patients may have initial plantar flexion of the great toe followed by sequential brief plantar flexion of the second, third, fourth, and fifth toes after snapping of one of the toes ("undulating toe flexion sign"). ${ }^{45}$

Confirmatory laboratory tests. Brain death is a clinical diagnosis. A repeat clinical evaluation 6 hours later is advised (option), but a firm recommendation cannot be given and the interval is arbitrary. ${ }^{15} \mathrm{~A}$ confirmatory test is not mandatory in most situations. All clinical tests are needed to declare brain death and are likely equally essential. (One should not prioritize individual brainstem tests.) A confirmatory test is needed for patients in whom specific components of clinical testing cannot be reliably evaluated. In some countries other than the United States, confirmatory tests are required by law (eg, Germany). ${ }^{5}$ Clinical experience with confirmatory tests other than EEG, transcranial Doppler ultrasonography, and conventional angiography is limited. Many studies did not use blind assessment of the results, did not assess interobserver variation, and did not perform tests in control subjects. In addition, many tests need costly equipment and well-trained technicians.

Confirmatory tests that are generally accepted are conventional angiography and EEG..$^{15}$ Consensus criteria are reported only for EEG and somatosensory evoked potentials. ${ }^{47}$ The Therapeutics and Technology Assessment Subcommittee of the AAN has accepted transcranial Doppler ultrasonography as a reliable procedure for confirmation of brain death. ${ }^{48}$

\section{Conventional angiography. ${ }^{49-54}$}

Technique. A selective four-vessel angiogram is done in the radiology suite. Iodinated contrast medium is injected under high pressure in both the anterior and the posterior circulations. The proce- 
dure takes a few hours.

Result. Intracerebral filling is absent at the level of the carotid bifurcation or circle of Willis. The external carotid circulation is patent, and at times delayed filling of the superior longitudinal sinus is seen.

Validity. Interobserver studies have not been published. The procedure has the potential to yield conflicting results because no guidelines for interpretation have been developed.

Disadvantage. Repeated contrast injections may increase the risk of nephrotoxicity and decrease the acceptance rate in organ recipients, but in general do not result in refusal of kidney donation.

\section{Electroencephalography. ${ }^{47,55-62}$}

Technique. Usually a 16- or 18-channel instrument is used with guidelines developed by the American Electroencephalographic Society for recording brain death. ${ }^{47,55}$

Result. No electrical activity occurs above $2 \mu \mathrm{V}$ at a sensitivity of $2 \mu \mathrm{V} / \mathrm{mm}$ with filter setting at 0.1 or 0.3 second and $70 \mathrm{~Hz}$. Recording should continue for at least 30 minutes.

Validity. Most patients meeting the clinical criteria for brain death have isoelectric EEGs. Nevertheless, in one consecutive series of patients fulfilling the clinical diagnosis of brain death, $20 \%$ of 56 patients had residual EEG activity that lasted up to 168 hours. ${ }^{60}$

Disadvantage. Considerable artifacts in the intensive care unit can limit interpretation. ${ }^{62}$

\section{Isotope angiography. ${ }^{63-65}$}

Technique. Rapid intravenous injection of serum albumin labeled with technetium $99 \mathrm{~m}$ is followed by bedside imaging with a portable gamma camera.

Result. Intracranial radioisotope activity is absent. Filling of sagittal and transverse sinuses may occur in delayed images from connections between the extracranial circulation and the venous system.

Validity. The sensitivity and specificity of lack of intracranial radioisotopes have not been defined in adults.

Disadvantage. The posterior cerebral circulation is not visualized.

\section{Technetium-99m hexamethylpropyleneamine-} oxime ( ${ }^{99 m}$ Tc-HMPAO).66-69

Technique. The procedure can be performed at the bedside and takes approximately 15 minutes. The isotope should be injected within 30 minutes of reconstitution. A portable gamma camera produces planar views within 5 to 10 minutes. Correct intravenous injection can be checked by taking additional chest and abdominal images.

Result. No uptake occurs in the brain parenchyma.

Validity. Experience with this technique is limited. Sensitivity of the brainstem has been reported to be as low as $94 \%$ with a specificity of $100 \% .{ }^{68} \mathrm{Re}-$ producibility has been tested in only a few patients. In one study, a correlation between cerebral an- giography and ${ }^{99 m}$ Tc-HMPAO scintigraphy was excellent. ${ }^{66}$

Disadvantages. The tracer should be injected immediately. Because the costs are currently high and the technique is not widely available, expertise is limited.

\section{Transcranial Doppler ultrasonography. 13,63,70.74}

Technique. A portable 2-MHz pulsed Doppler instrument can be used at the bedside. Intracranial arteries should be insonated bilaterally (eg, middle cerebral artery through the temporal bone above the zygomatic arch and the vertebral or basilar arteries through the suboccipital transcranial window ${ }^{13,70}$; alternatively, a combination of one ophthalmic artery through the transorbital window and the middle cerebral artery can be tried ${ }^{13,70}$ ).

Result. Transcranial Doppler signals that have been reported in brain death are as follows: (1) Absent diastolic or reverberating flow that indicates flow only through systole or retrograde diastolic flow. This pattern is caused by the contractive forces of the arteries. (2) Small systolic peaks in early systole that indicate very high vascular resistance. This pattern is associated with greatly increased intracranial pressure. Lack of transcranial Doppler signals cannot be interpreted as confirmatory of brain death, because $10 \%$ of patients may not have temporal insonation windows. An exception possibly can be made in patients who had transcranial Doppler signals during admission that disappeared at the time of brain death.

Validity. There is a comparatively large experience with transcranial Doppler ultrasonography in the confirmation of brain death. ${ }^{13,70,71,75}$ The sensitivity of the procedure is $91.3 \%$ and the specificity is $100 \%$. Transcranial Doppler ultrasonography occasionally demonstrates "brain death patterns" in patients who are clinically brain-dead and who have EEG activity. ${ }^{13,70}$ Small systolic peaks and increased diastolic flow may occur as transient phenomena in patients with aneurysmal rerupture. ${ }^{72}$ Transcranial Doppler signals can be normal in patients with primary infratentorial lesions and in patients with anoxic-ischemic damage after cardiac arrest. ${ }^{13}$

Disadvantages. Transcranial Doppler velocities can be affected by marked changes in $\mathrm{PCO}_{2}$, hematocrit, and cardiac output. ${ }^{13}$ Transcranial Doppler ultrasonography requires considerable practice and skill.

\section{Somatosensory evoked potentials.}

Technique. A portable instrument can be used at the bedside. Median nerve stimulation is performed on both sides.

Result. N20-P22 response is bilaterally absent.

Validity. Somatosensory evoked potentials and auditory brainstem responses were tested in patients with brain death, and most patients were found to have no responses. ${ }^{76-86}$ One study ${ }^{76}$ claimed that both flat brainstem auditory evoked potentials 
and absence of somatosensory evoked potentials beyond Erb's point were unique in patients with brain death and not found in comatose patients who still had preserved brainstem function. This study has not been confirmed or refuted.

Miscellaneous tests. Many of these tests have been done in small series of patients only and are not widely adopted as confirmatory tests.

Contrast CT with a bolus of meglumine diatrizoate, $1 \mathrm{ml} / \mathrm{kg}$ of body weight, followed by drip infusion of $0.02 \mathrm{ml} / \mathrm{kg}$ per minute, does not visualize intracranial vessels. ${ }^{87-90} \mathrm{~A}$ good correlation with cerebral angiography has been demonstrated in a few anecdotal reports. ${ }^{89}$

Many other confirmatory tests are variants or modifications. Experience is limited, or these tests produce similar results in patients with neurologic catastrophes who do not fulfill the clinical criteria for brain death.

\section{Recommendations after the diagnosis of} brain death. It is prudent to discuss organ donation with family members only after the clinical diagnosis of brain death. The following approach is suggested. The family should be told in unequivocal terms that the patient died. Mechanical ventilation, fluids, and blood pressure medication are administered only to procure organs in the event that permission for donation is given. Refusal by family members to harvest organs removes the rationale for supportive therapy, and mechanical ventilation is discontinued after the family has been allowed adequate time for consideration and visitation. When the family permits organ procurement, a local transplantation coordinator is notified.

Management of a brain-dead patient in preparation for donation is complicated, and advice from a neurologist specialized in neurologic critical care or from an anesthesiologist should be strongly considered..$^{91-94}$

Major immediate threats to organs are (1) pulmonary edema, requiring pulmonary artery catheter placement and treatment with positive end-expiratory pressure ventilation, (2) hypotension, requiring adequate fluid resuscitation and vasopressors (dopamine to $10 \mu \mathrm{g} / \mathrm{kg}$ per millimeter), (3) polyuria from diabetes insipidus, ${ }^{95}$ requiring 1-desamino-8-D-arginine vasopressin (1 to $4 \mu \mathrm{g}$ ) or desmopressin ( 0.5 to $2 \mu \mathrm{g}$ ) intravenously every 8 hours and guidance by urine output. Use of hormone substitution and prophylactic administration of antibiotics is controversial..$^{91-94}$

Recommendation for future research. Data on apnea testing are incomplete, and careful evaluation of respiratory efforts and the level of $\mathrm{PCO}_{2}$ at which apnea occurs is necessary. Confirmatory test results need to be validated.

\section{Acknowledgments}

Many neurologists have reviewed the manuscript. I am particu- larly grateful for the critical reviews by Drs. S. Ashwal, J.L Bernat, T.P. Bleck, J.R. Daube, M. Diringer, D. Hanley, A.H Ropper, and M.R. Nuwer. Joanne F. Okagaki's expertise is greatly acknowledged.

References (roman numbers in parentheses identify class II or III studies)

1. (III) American Academy of Pediatrics. Report of special task force: guidelines for the determination of brain death in children. Pediatrics 1987;80:298-300.

2. (III) Lynch J, EIdadah MK. Brain-death criteria currently used by pediatric intensivists. Clin Pediatr 1992;31:457-460.

3. (III) Black PMcL. Brain death (parts 1 and 2). N Engl J Med 1978;299:338-344,393-401.

4. (III) Pallis C. ABC of brain stem death: the position in the USA and elsewhere. Br Med J 1983;286:209-210.

5. (III) Pallis C. Brainstem death. In: Braakman R, ed. Head injury. Handbook of clinical neurology, vol 57. Amsterdam: Elsevier Science, 1990:441-496.

6. (III) Walker AE. Cerebral death. 2nd ed. Baltimore: Urban \& Schwarzenberg, 1981.

7. (II) Snyder BD, Gumnit RJ, Leppik IE, Hauser WA, Loewenson RB, Ramirez-Lassepas M. Neurologic prognosis after cardiopulmonary arrest: IV. Brainstem reflexes. Neurology 1981;31:1092-1097

8. (II) Levy DE, Caronna JJ, Singer BH, Lapinski RH, Frydman $\mathrm{H}$, Plum F. Predicting outcome from hypoxic-ischemic coma. JAMA 1985;253:1420-1426.

9. (II) Lidofsky SD, Bass NM, Prager MC, et al. Intracranial pressure monitoring and liver transplantation for fulminant hepatic failure. Hepatology 1992;16:1-7.

10. (II) Belsh JM, Blatt R, Schiffman PL. Apnea testing in brain death. Arch Intern Med 1986;146:2385-2388.

(III) Earnest MP, Beresford HR, McIntyre HB. Testing for apnea in suspected brain death: methods used by 129 clinicians. Neurology 1986;36:542-544.

12. (III) Jennett B, Gleave J, Wilson P. Brain death in three neurosurgical units. Br Med J 1981;282:533-539.

13. (II) Petty GW, Mohr JP, Pedley TA, et al. The role of transcranial Doppler in confirming brain death: sensitivity, specificity, and suggestions for performance and interpretation. Neurology 1990;40:300-303.

14. (III) Ropper AH. Unusual spontaneous movements in braindead patients. Neurology 1984;34:1089-1092.

15. (III) Guidelines for the determination of death: report of the Medical Consultants on the Diagnosis of Death to the President's Commission for the Study of Ethical Problems in Medicine and Biomedical and Behavioral Research. JAMA 1981;246:2184-2186.

16. (II) Fischbeck $\mathrm{KH}$, Simon RP. Neurological manifestations of accidental hypothermia. Ann Neurol 1981;10:384-387.

17. (III) LaMancusa T, Cooper $R$, Vieth $R$, Wright $F$. The effects of the falling therapeutic and subtherapeutic barbiturate blood levels on electrocerebral silence in clinical brain-dead children. Clin Electroencephalogr 1991;22:112-117.

18. (III) Pallis CA, Prior PF. Guidelines for the determination of death [letter]. Neurology 1983;33:251-252.

19. (III) Molinari GF. Review of clinical criteria of brain death Ann NY Acad Sci 1978;315:62-69.

20. (III) Ad Hoc Committee of the Harvard Medical School to Examine the Definition of Brain Death. A definition of irreversible coma. JAMA 1968;205:337-340.

21. (II) Ropper AH, Kennedy SK, Russell L. Apnea testing in the diagnosis of brain death: clinical and physiological observations. J Neurosurg 1981;55:942-946.

22. (II) Bruce EN, Cherniack NS. Central chemoreceptors. J Appl Physiol 1987;62:389-402.

23. (II) Frumin MJ, Epstein RM, Cohen G. Apnoeic oxygenation in man. Anesthesiology 1959;20:789-798.

24. (II) Ivanov SD, Nunn JF. Methods of elevation of $\mathrm{PCO}_{2}$ for restoration of spontaneous breathing after artificial ventilation of anaesthetized patients. Br J Anaesth 1969;41:28-37.

25. (II) Engel GL, Ferris EB, Webb JP, Stevens CD. Voluntary 
breathholding. II. The relation of the maximum time of breathholding to the oxygen tension of the inspired air. $J$ Clin Invest 1946;25:729-733.

26. (II) Ferris EB, Engel GL, Stevens CD, Webb J. Voluntary breathholding. III. The relation of the maximum time of breathholding to the oxygen and carbon dioxide tensions of arterial blood, with a note on its clinical and physiological significance. J Clin Invest 1946;25:734-743.

27. (II) Prechter GC, Nelson SB, Hubmayr RD. The ventilatory recruitment threshold for carbon dioxide. Am Rev Respir Dis 1990;141:758-764.

28. (III) Glauser FL, Fairman RP, Bechard D. The causes and evaluation of chronic hypercapnea. Chest 1987;91:755-759

29. (III) Rohling R, Wagner W, Mühlberg J, Link J, Scholle J, Rosenow D. Apnea test: pitfalls and correct handling. Transplant Proc 1986;18:388-390.

30. (II) Marks SJ, Zisfein J. Apneic oxygenation in apnea tests for brain death: a controlled trial. Arch Neurol 1990; 47:1066-1068

31. (II) Eger EI, Severinghaus JW. The rate of rise of $\mathrm{PACO}_{2}$ in the apneic anesthetized patient. Anesthesiology 1961;22: 419-425.

32. (II) Benzel EC, Mashburn JP, Conrad S, Modling D. Apnea testing for the determination of brain death: a modified protocol. J Neurosurg 1992;76:1029-1031.

33. (III) Ebata T, Watanabe Y, Amaha K, Hosaka Y, Takagi S. Haemodynamic changes during the apnoea test for diagnosis of brain death. Can J Anaesth 1991;38:436-440.

34. (II) Jeret JS, Benjamin JL. Risk of hypotension during apnea testing. Arch Neurol 1994;51:595-599.

35. (II) Segredo V, Caldwell JE, Matthay MA, Sharma ML, Gruenke LD, Miller RD. Persistent paralysis in critically ill patients after long-term administration of vecuronium. N Engl J Med 1992;327:524-528.

36. (III) Partridge BL, Abrams JH, Bazemore C, Rubin R. Prolonged neuromuscular blockade after long-term infusion of vecuronium bromide in the intensive care unit. Crit Care Med 1990;18:1177-1179.

37. (III) Sims JK, Bickford RG. Non-mydriatic pupils occurring in human brain death. Bull Los Angeles Neurol Soc 1973;38:24-32.

38. (II) Goetting MG, Contreras E. Systemic atropine administration during cardiac arrest does not cause fixed and dilated pupils. Ann Emerg Med 1991;20:55-57.

39. (II) Greenan J, Prasad J. Comparison of the ocular effects of atropine and glycopyrrolate with two IV induction agents. $\mathrm{Br}$ J Anaesth 1985;57:180-183.

40. (III) Ong GL, Bruning HA. Dilated fixed pupils due to administration of high doses of dopamine hydrochloride. Crit Care Med 1981;9:658-659.

41. (III) Snavely SR, Hodges GR. The neurotoxicity of antibacterial agents. Ann Intern Med 1984;101:92-104

42. (III) Jordan JE, Dyess E, Cliett J. Unusual spontaneous movements in brain-dead patients [letter]. Neurology 1985; 35:1082.

43. (III) Jørgensen EO. Spinal man after brain death: the unilateral extension-pronation reflex of the upper limb as an indication of brain death. Acta Neurochir (Wien) 1973;28:259 273.

44. (III) Kuwagata Y, Sugimoto H, Yoshioka T, Sugimoto T Hemodynamic response with passive neck flexion in brain death. Neurosurgery 1991;29:239-241.

45. (III) McNair NL, Meador $\mathrm{K}$. The undulating toe flexion sign in brain death. Mov Disord 1992;7:345-347.

46. (III) Conci F, Procaccio F, Arosio M, Boselli L. Viscero somatic and viscero-visceral reflexes in brain death. $J$ Neurol Neurosurg Psychiatry 1986;49:695-698.

47. (III) Guideline Three. Minimum technical standards for EEG recording in suspected cerebral death. J Clin Neurophysiol 1994;11:10-13.

48. (III) American Academy of Neurology, Therapeutics and Technology Assessment Subcommittee. Assessment: transcranial Doppler. Neurology 1990;40:680-681.

49. (II) Cantu RC. Brain death as determined by cerebral arteriography [letter]. Lancet 1973;1:1391-1392.

50. (II) Bradac GB, Simon RS. Angiography in brain death
Neuroradiology 1974;7:25-28.

51. (II) Kricheff II, Pinto RS, George AE, Braunstein P, Korein J. Angiographic findings in brain death. Ann NY Acad Sci 1978;315:168-183.

52. (III) Langfitt TW, Kassell NF. Non-filling of cerebral vessels during angiography: correlation with intracranial pressure. Acta Neurochir (Wien) 1966;14:96-104.

53. (II) Greitz T, Gordon E, Kolmodin G, Widén L. Aortocranial and carotid angiography in determination of brain death. Neuroradiology 1973;5:13-19.

54. (II) Hazratji SM, Singh BM, Strobos RJ. Angiography in brain death. NY State J Med 1981;81:82-83.

55. (III) Silverman D, Saunders MG, Schwab RS, Marana RL. Cerebral death and the electroencephalogram. Report of the Ad Hoc Committee of the American Electroencephalographic Society on EEG criteria for determination of cerebral death. JAMA 1969;209:1505-1510.

56. (III) Bennett DR. The EEG in determination of brain death. Ann NY Acad Sci 1978;315:110-119.

57. (II) Buchner H, Schuchardt V. Reliability of electroencephalogram in the diagnosis of brain death. Eur Neurol 1990;30:138-141.

58. (III) Jørgensen EO. Requirements for recording the EEG at high sensitivity in suspected brain death. Electroencephalogr Clin Neurophysiol 1974;36:65-69.

59. (II) Korein J, Maccario M. A prospective study on the diagnosis of cerebral death [abstract]. Electroencephalogr Clin Neurophysiol 1971;31:103-104.

60. (II) Grigg MA, Kelly MA, Celesia GG, Ghobrial MW, Ross ER. Electroencephalographic activity after brain death. Arch Neurol 1987;44:948-954.

61. (III) Hughes JR. Limitations of the EEG in coma and brain death. Ann NY Acad Sci 1978;315:121-136.

62. (III) Deliyannakis E, Ioannou F, Davaroukas A. Brain stem death with persistence of bioelectric activity of the cerebral hemispheres. Clin Electroencephalogr 1975;6:75-79.

63. (II) Goodman JM, Heck LL, Moore BD. Confirmation of brain death with portable isotope angiography: a review of 204 consecutive cases. Neurosurgery 1985;16:492-497.

64. (II) Korein J, Braunstein P, Kricheff I, Lieberman A, Chase N. Radioisotopic bolus technique as a test to detect circulatory deficit associated with cerebral death: 142 studies on 80 patients demonstrating the bedside use of an innocuous IV procedure as an adjunct in the diagnosis of cerebral death. Circulation 1975;51:924-939.

65. (II) Korein J, Braunstein P, George A, et al. Brain death. I, Angiographic correlation with a radioisotopic bolus technique for evaluation of critical deficit of cerebral blood flow. Ann Neurol 1977;2:195-205.

66. (III) George MS. Establishing brain death: the potential role of nuclear medicine in the search for a reliable confirmatory test. Eur J Nucl Med 1991;18:75-77.

67. (III) Yatim A, Mercatello A, Coronel B, et al. ${ }^{99 m}$ Tc-HMPAO cerebral scintigraphy in the diagnosis of brain death. Transplant Proc 1991;23:2491.

68. (III) Laurin NR, Driedger AA, Hurwitz GA, et al. Cerebral perfusion imaging with technetium-99m HM-PAO in brain death and severe central nervous system injury. J Nucl Med 1989;30:1627-1635.

69. (III) Roine RO, Launes J, Lindroth L, Nikkinen P. ${ }^{99 \mathrm{~m}} \mathrm{Tc}$ hexamethylpropyleneamine oxime scans to confirm brain death [letter]. Lancet 1986;2:1223-1224.

70. (II) Ropper AH, Kehne SM, Wechsler L. Transcranial Doppler in brain death. Neurology 1987;37:1733-1735.

71. (II) Saunders FW, Cledgett P. Intracranial blood velocity in head injury: a transcranial ultrasound Doppler study. Surg Neurol 1988;29:401-409.

72. (II) Hassler W, Steinmetz H, Gawlowski J. Transcranial Doppler ultrasonography in raised intracranial pressure and in intracranial circulatory arrest. J Neurosurg 1988;68:745751

73. (II) Van Velthoven V, Calliauw L. Diagnosis of brain death: transcranial Doppler sonography as an additional method. Acta Neurochir (Wien) 1988;95:57-60.

74. (III) Powers AD, Graeber MC, Smith RR. Transcranial Doppler ultrasonography in the determination of brain 
death. Neurosurgery 1989;24:884-889.

75. (II) Klingelhöfer J, Conrad B, Benecke R, Sander D, Markakis E. Evaluation of intracranial pressure from transcranial Doppler studies in cerebral disease. J Neurol 1988;235:159-162.

76. (II) Goldie WD, Chiappa KH, Young RR, Brooks EB. Brainstem auditory and short-latency somatosensory evoked responses in brain death. Neurology 1981;31:248-256.

77. (II) Garcia-Larrea L, Bertrand O, Artru F, Pernier J, Mauguière F. Brain-stem monitoring. Il. Preterminal BAEP changes observed until brain death in deeply comatose patients. Electroencephalogr Clin Neurophysiol 1987;68:446-457.

78. (II) Starr A. Auditory brain-stem responses in brain death. Brain 1976;99:543-554.

79. (II) Wagner W. SEP testing in deeply comatose and brain dead patients: the role of nasopharyngeal, scalp and earlobe derivations in recording the P14 potential. Electroencephalogr Clin Neurophysiol 1991;80:352-363.

80. (II) Machado C, Valdés P, García-Tigera J, et al. Brain stem auditory evoked potentials and brain death. Electroencephalogr Clin Neurophysiol 1991;80:392-398.

81. (II) Anziska BJ, Cracco RQ. Short latency somatosensory evoked potentials in brain dead patients. Arch Neurol 1980;37:222-225.

82. (II) Stöhr M, Riffel B, Trost E, Ullrich A. Short-latency somatosensory evoked potentials in brain death. $J$ Neurol 1987;234:211-214.

83. (III) Ferbert A, Buchner H, Ringelstein EB, Hacke W. Isolated brain-stem death: case report with demonstration of preserved visual evoked potentials (VEPs). Electroencephalogr Clin Neurophysiol 1986;65:157-160.

84. (II) Firsching $\mathrm{R}$. The brain-stem and $40 \mathrm{~Hz}$ middle latency auditory evoked potentials in brain death. Acta Neurochir
(Wien) 1989;101:52-55.

85. (II) Chancellor AM, Frith RW, Shaw NA. Somatosensory evoked potentials following severe head injury: loss of the thalamic potential with brain death. J Neurol Sci 1988; 87:255-263.

86. (II) Belsh JM, Chokroverty S. Short-latency somatosensory evoked potentials in brain-dead patients. Electroencephalogr Clin Neurophysiol 1987;68:75-78.

87. (III) Rangel RA. Computerized axial tomography in brain death. Stroke 1978;9:597-598.

88. (III) Rappaport ZH, Brinker RA, Rovit RL. Evaluation of brain death by contrast-enhanced computerized cranial tomography. Neurosurgery 1978;2:230-232.

89. (III) Arnold H, Kühne D, Rohr W, Heller M. Contrast bolus technique with rapid CT scanning: a reliable diagnostic tool for the determination of brain death. Neuroradiology 1981;22:129-132.

90. (III) Handa J, Matsuda M, Matsuda I, Nakasu S. Dynamic computed tomography in brain death. Surg Neurol 1982; $17: 417-422$

91. (III) Darby JM, Stein K, Grenvik A, Stuart SA. Approach to management of the heart-beating "brain dead" organ donor. JAMA 1989;261:2222-2228.

92. (III) Slapak M. The immediate care of potential donors for cadaver organ transplantation. Anaesthesia 1978;33:700709

93. (II) Jordan CA, Snyder JV. Intensive care and intraoperative management of the brain-dead organ donor. Transplant Proc 1987;19(suppl 3):21-25.

94. (III) Lindop MJ. Basic principles of donor management for multiorgan removal. Transplant Proc 1991;23:2463-2464.

95. (III $>$ Pallis $\mathrm{C}$. Diabetes insipidus with brain death [letter] Neurology 1985;35:1086-1087.

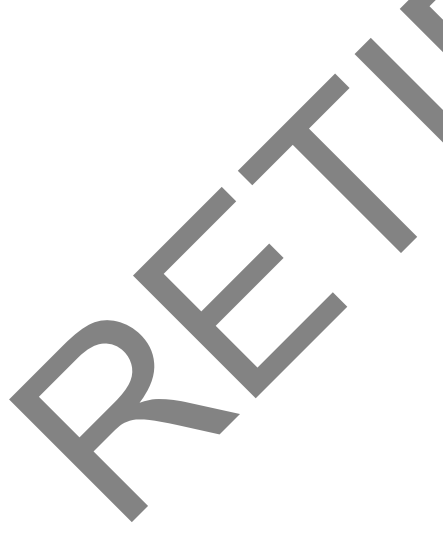




\title{
Neurology
}

\author{
Determining brain death in adults [RETIRED] \\ Eelco F.M. Wijdicks \\ Neurology 1995;45;1003-1011 \\ DOI 10.1212/WNL.45.5.1003
}

\section{This information is current as of May 1, 1995}

\section{Updated Information \& Services}

\section{Citations}

Permissions \& Licensing

Reprints including high resolution figures, can be found at: http://n.neurology.org/content/45/5/1003.full

This article has been cited by 27 HighWire-hosted articles: http://n.neurology.org/content/45/5/1003.full\#\#otherarticles

Information about reproducing this article in parts (figures,tables) or in its entirety can be found online at:

http://www.neurology.org/about/about_the_journal\#permissions

Information about ordering reprints can be found online:

http://n.neurology.org/subscribers/advertise

Neurology $®$ is the official journal of the American Academy of Neurology. Published continuously since 1951, it is now a weekly with 48 issues per year. Copyright Copyright 1995 by Advanstar Communications Inc.. All rights reserved. Print ISSN: 0028-3878. Online ISSN: 1526-632X.

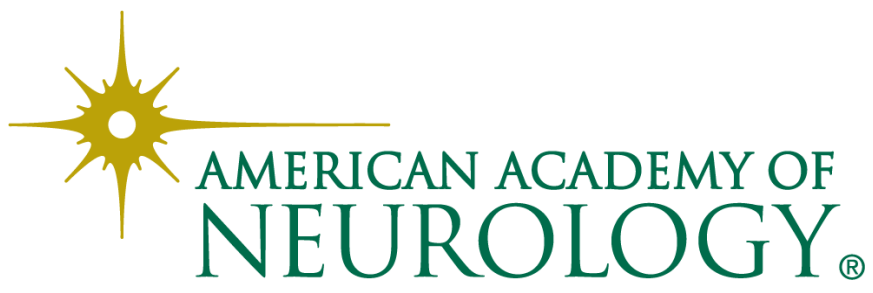

